\title{
Notas Científicas \\ Embriões de pacu submetidos a diferentes protocolos de resfriamento
}

\author{
Danilo Pedro Streit Júnior ${ }^{(1)}$, Melanie Digmayer ${ }^{(2)}$, Ricardo Pereira Ribeiro(2), Rodolfo Nardez Sirol(3), \\ Gentil Vanini de Moraes $^{(2)}$ e Juliana Minardi Galo(2)
}

\begin{abstract}
(1)Universidade Federal do Rio Grande do Sul, Fac. de Agronomia, Dep. de Zootecnia, Lab. de Aquacultura, Av. Bento Gonçalves, no 7.712, CEP 91540-000 Porto Alegre, RS. E-mail: danilo.streit@ufrgs.br (2)Universidade Estadual de Maringá, Dep. de Zootecnia, Lab. de Reprodução Animal, Av. Colombo, no 5.790, CEP 87020-900 Maringá, PR. E-mail: melanie_digmayer@hotmail.com, rpribeiro@uem.br, gvmoraes@uem.br, juliminardi@hotmail.com ${ }^{(3)}$ Duke Energy Geração Paranapanema S.A., Gerência de Meio Ambiente, Rod. Chavantes, Km 10, Ribeirão Claro, CEP 18970-000 Chavantes, SP. E-mail: rnsirol@duke-energy.com
\end{abstract}

Resumo - O objetivo deste trabalho foi avaliar a taxa de eclosão de larvas de pacu (Piaractus mesopotamicus), após o resfriamento dos embriões a $-8^{\circ} \mathrm{C}$ durante seis horas, utilizando soluções crioprotetoras, para obter um protocolo de resfriamento para a espécie. Utilizaram-se 2.400 embriões em estádio de pós-gástrula, em sete tratamentos de soluções crioprotetoras, mais um controle, com três repetições, em delineamento inteiramente casualizado. Os crioprotetores etilenoglicol e geléia real foram inapropriados. A substituição de $50 \%$ da sacarose não produziu resultados positivos. A combinação metanol (9\%) e sacarose (17,5\%) possibilitou eclosão de $69,2 \%$, sendo recomendada para o resfriamento a $-8^{\circ} \mathrm{C}$ de embriões de pacu por seis horas.

Termos para indexação: Piaractus mesopotamicus, crioprotetor, embrião de peixe, refrigeração, taxa de eclosão.

\section{Pacu embryos submitted to different cooling protocols}

\begin{abstract}
The objective of this work was to evaluate the percentage of hatching after cooling of pacu (Piaractus mesopotamicus) embryos at $-8^{\circ} \mathrm{C}$ for six hours, treated with cryoprotectant solutions, to obtain a cooling protocol for the specie. There were 2.400 embryos in post-gastrula stage development, in seven cryoprotectants solutions and control with three replicates, in completely randomized design. Ethylene glycol and honey-jelly were inappropriate. The substitution of 50\% sucrose did not produce positive results. The combination of methanol (9\%) and sucrose (17.5\%) performed $69.2 \%$ of hatching and is recommended for cooling of pacu embryos at $-8{ }^{\circ} \mathrm{C}$ for six hours.
\end{abstract}

Index terms: Piaractus mesopotamicus, cryoprotectant, fish embryos, cooling, hatching rate.

O desenvolvimento e aplicação de um protocolo de resfriamento de embriões possibilita inúmeras aplicações no setor de produção de alevinos, como o transporte de embriões obtidos em locais remotos, por exemplo, cabeceiras de rios, em refrigerador para a incubação em laboratório (Ahammad et al., 2003), a minimização da assincronia dos reprodutores durante o período reprodutivo e a otimização de incubadoras em laboratório.

No Brasil, espécies nativas têm sido utilizadas na piscicultura com boa resposta. Entre essas espécies o pacu (Piaractus mesopotamicus) apresenta excelentes características zootécnicas para a criação (Castagnolli, 1992) e, de acordo com dados do Ibama (2004), o pacu é a segunda espécie nativa mais cultivada no Brasil.
Porém, novas tecnologias podem contribuir diretamente com a produção dessa espécie.

Para o desenvolvimento de um protocolo de resfriamento, soluções crioprotetoras são indispensáveis de modo a submeter o embrião a temperaturas abaixo de $0^{\circ} \mathrm{C}$. Os agentes crioprotetores podem ser classificados em razão de sua ação intracelular (metanol, DMSO, glicerol, etilenoglicol) ou extracelular (glicose, sacarose, trehalose). Entretanto, de acordo com Denniston et al. (2000), o desempenho de um crioprotetor intracelular pode ser otimizado quando se associa crioprotetores de ação extracelular.

O objetivo deste trabalho foi avaliar a taxa de eclosão de larvas de P. mesopotamicus, após o resfriamento dos 
embriões a $-8^{\circ} \mathrm{C}$ durante seis horas, utilizando-se soluções crioprotetoras, a fim de obter um protocolo de resfriamento para a espécie.

O trabalho foi conduzido em fevereiro de 2006, na Estação de Hidrologia e Aqüicultura da Duke Energy, Geração Paranapanema, no Município de Salto Grande, SP, em parceria com o laboratório de reprodução animal da Universidade Estadual de Maringá.

Para obtenção dos embriões, 20 fêmeas e 20 machos foram induzidos com extrato de hipófise de carpa e submetidos a desova semi-natural. Após a liberação dos gametas e fertilização no próprio tanque de reprodução natural, os ovos foram recolhidos e distribuídos em 47 incubadoras do tipo Israel de $7 \mathrm{~L}$ com fluxo de $5 \mathrm{~L}$ por minuto. Nessas incubadoras, selecionaram-se 2.400 embriões viáveis de pacu em estádio de pós-gástrula, após o fechamento do blastóporo.

$\mathrm{O}$ experimento foi conduzido em delineamento inteiramente casualizado, com sete tratamentos e um controle (embriões incubados em água sem passar pelo resfriamento), com três repetições. Cada repetição foi considerada uma unidade experimental. Os crioprotetores extracelulares utilizados foram glicose e geléia real e os intracelulares, metanol e etilenoglicol em diferentes proporções. Os tratamentos foram: T1, 17,1\% sacarose $+9 \%$ metanol $+26,1 \%$ água; $\mathrm{T} 2,17,1 \%$ sacarose $+9 \%$ etilenoglicol $+26,1 \%$ água; T3, $17,1 \%$ sacarose $+9 \%$ metanol $+1 \%$ geléia real $+27,1 \%$ água; $\mathrm{T} 4,17,1 \%$ sacarose $+9 \%$ etilenoglicol $+1 \%$ geléia real $+27,1 \%$ água; $\mathrm{T} 5,8,5 \%$ sacarose $+8,5 \%$ glicose $+9 \%$ metanol $+26 \%$ água; T6, $8,5 \%$ sacarose $+8,5 \%$ glicose $+9 \%$ etilenoglicol + 26\% água; T7, $100 \%$ água.

Os 2.400 embriões, em água à temperatura de $28^{\circ} \mathrm{C}$, foram subdivididos em 24 parcelas com 100 embriões cada, alocadas em 24 diferentes tubos de vidro vacutainer com $20 \mathrm{~mL}$ das sete diferentes soluções crioprotetoras e da água para o controle.

Adotou-se o método de resfriamento lento dos embriões, utilizado por Ahammad et al. (2003) em embriões de Cyprinus carpio. Com exceção dos tubos do controle, os demais 21 tubos, depois de vedados, foram resfriados em recipiente contendo água a $15^{\circ} \mathrm{C}$, durante 10 minutos. Em seguida, os tubos transferidos a outro recipiente com água a $5^{\circ} \mathrm{C}$, durante 10 minutos para posterior acondicionamento em congelador a $-8^{\circ} \mathrm{C}$, por seis horas. Em seguida, os tubos foram retirados, as soluções contidas em seu interior foram drenadas e os embriões transferidos para incubadoras de $7 \mathrm{~L}$, onde já estava o controle, para completar o desenvolvimento. No tratamento T7, que continha apenas água, ocorreu formação de gelo. Nos demais tratamentos, os tubos de vidro foram colocados ainda vedados dentro da incubadora por dois minutos e, após, os embriões foram depositados na água da incubadora para completar o seu desenvolvimento.

No início da eclosão das larvas do controle (18 horas), estabeleceu-se um período de nove horas para avaliação dos demais tratamentos. As larvas e ovos gorados foram retirados das incubadoras para avaliação.

O modelo proposto foi: $Y i j=\mu+\mathrm{Ti}+$ eij, em que Yij é a observação (j) do tratamento (i); $\mu$ é a constante geral; Ti é o efeito do tratamento (i); eij é o erro associado à observação (j) submetido ao tratamento (i).

Nas análises estatísticas, utilizou-se o procedimento Genmod do SAS (SAS Institute, 1992), que implementou o método Modelos Lineares Generalizados. Considerouse que os erros possuíam distribuição de probabilidade de Poisson, com função de ligação logarítmica.

Não houve diferença significativa $(\mathrm{p}>0,05)$ na taxa de eclosão das larvas entre o grupo controle e o tratamento T1, no qual utilizou-se sacarose com o metanol. Em relação aos demais tratamentos, porém, o controle apresentou taxa de eclosão significativamente maior $(\mathrm{p}<0,05)$ (Tabela 1).

Tabela 1. Taxa de eclosão de larvas de Piaractus mesopotamicus, após resfriamento de embriões a $-8^{\circ} \mathrm{C}$ por seis horas, com diferentes tratamentos de soluções crioprotetoras.

\begin{tabular}{lc}
\hline Tratamento $^{(1)}$ & ${\text { Taxa de eclosão }(\%)^{(2)}}^{\text {Controle }}$ \\
T1 & $80,0 \mathrm{a}$ \\
T2 & $69,2 \mathrm{a}$ \\
T3 & $0,0 \mathrm{~d}$ \\
T4 & $2,0 \mathrm{~d}$ \\
T5 & $0,0 \mathrm{~d}$ \\
T6 & $18,2 \mathrm{~b}$ \\
T7 & $0,0 \mathrm{~d}$ \\
\hline
\end{tabular}

${ }^{(1)}$ Controle, embriões incubados em água sem processo de resfriamento; $\mathrm{T} 1,17,1 \%$ sacarose $+9 \%$ metanol $+26,1 \%$ água; $\mathrm{T} 2,17,1 \%$ sacarose $+9 \%$ etilenoglicol $+26,1 \%$ água; $\mathrm{T} 3,17,1 \%$ sacarose $+9 \%$ metanol $+1 \%$ geléia real $+27,1 \%$ água; $\mathrm{T} 4,17,1 \%$ sacarose $+9 \%$ etilenoglicol $+1 \%$ geléia real $+27,1 \%$ água; $\mathrm{T} 5,8,5 \%$ sacarose $+8,5 \%$ glicose $+9 \%$ metanol $+26 \%$ água; $\mathrm{T} 6,8,5 \%$ sacarose $+8,5 \%$ glicose $+9 \%$ etileno-glicol $+26 \%$ água; T7, 100\% água. ${ }^{(2)}$ Médias seguidas de letras iguais não diferem entre si a $5 \%$ de probabilidade. 
De modo geral, nas soluções em que foi utilizado o metanol como crioprotetor intracelular (T1, T3 e T5), a taxa de eclosão foi superior àquela em que o crioprotetor intracelular foi o etilenoglicol (T2, T4 e T6), especialmente quando sacarose foi acrescentada à solução crioprotetora (T1). A ação positiva do metanol como crioprotetor para embriões de peixes, sobretudo em soluções que contenham sacarose, tem sido verificada em outras espécies. Ahammad et al. (1998) encontraram alta taxa de sobrevivência com embriões de três espécies de carpa (Labeo rohita, Catla catla e Cirrhinus mrigala), quando estocados a $-4^{\circ} \mathrm{C}$, após serem tratados com metanol $(3,2,6,5$ e $9,7 \%)$, e sacarose $(17,1 \%)$. Esses autores concluíram que a adição de sacarose à solução de metanol (3,2 e $6,5 \%$ ) foi essencial para a sobrevivência dos embriões de Cirrhinus mrigala, mas dispensável aos embriões das outras duas espécies de carpa estudadas.

Propriedades positivas da sacarose, quando utilizada com outro crioprotetor extracelular, são destacadas por Woelders (1997), que considera como principal a estabilidade da membrana celular, especialmente no que se refere à deformação mecânica provocada por efluxo de água e o influxo de crioprotetor intracelular. Este fato é evidenciado por Farkas et al. (2001), que deixam clara a necessidade da manutenção estrutural e funcional da camada fosfolipídica, quando a estrutura está sendo exposta a uma nova temperatura.

A toxidez do crioprotetor etilenoglicol é reforçada pelo resultado obtido no tratamento $\mathrm{T} 7$, em que se utilizou apenas água sem crioprotetor, resultando em taxa de eclosão das larvas de 6\% (Tabela 1). A nãoocorrência de eclosão nos tratamentos T2, T4 e T6 com etilenoglicol pode estar relacionada à interferência desse crioprotetor no metabolismo do embrião, provocando desestruturação celular e conseqüentemente, morte. De acordo com Kusuda et al. (2002), a susceptibilidade dos embriões ocorre em função da degeneração celular e das proteínas da membrana nuclear, em virtude da desidratação e aumento na concentração salina decorrentes do contato com o crioprotetor.

A substituição parcial da sacarose por outro crioprotetor extracelular, no caso a glicose associada ao metanol (T5) e etilenoglicol (T6), foi ineficiente para o resfriamento de embriões de P. mesopotamicus, como se verificou na baixa taxa de eclosão observada,
18,2 e $0 \%$, respectivamente. Este fato fica evidenciado se comparado com a taxa de eclosão no tratamento (T1), 69,2\%, em que se utilizou apenas a sacarose como agente crioprotetor extracelular. Os açucares têm importante atuação na solução crioprotetora, que é a manutenção da pressão osmótica (Holt, 2000). A eficiência da sacarose como crioprotetor extracelular em relação à glicose, neste trabalho, pode estar relacionada ao fato de a sacarose, que é um oligossacarídeo, ter um efeito adicional de proteção celular sobre outros açucares de cadeia mais simples, como a glicose, por provocar desidratação nos embriões, evitando a formação de cristais de gelo intracelular (Rall, 1987).

A geléia real foi utilizada como agente crioprotetor para embriões de peixes, nos tratamentos $\mathrm{T} 3$ e $\mathrm{T} 4$ devido a sua propriedade em reduzir danos provocados pelo frio em embriões de mamíferos (Visintin et al., 2000). Todavia, em embriões de $P$. mesopotamicus, essa ação crioprotetora da geléia real não foi verificada. A taxa de eclosão do tratamento T3 (2\%) a $1 \%$ de geléia real associada ao metanol e à sacarose foi menor do que a taxa observada no tratamento T1 $(69,2 \%)$ sem geléia real na solução crioprotetora. Desse modo, atribui-se efeito nocivo da geléia real em relação aos embriões de P. mesopotamicus, à concentração de $1 \%$.

Um bom protocolo de resfriamento deve possibilitar a manutenção da viabilidade dos embriões resfriados pelo maior período de tempo possível. Neste trabalho, o tempo de seis horas foi alcançado com sucesso, possibilitando vislumbrar maior tempo de exposição dos embriões de pacu ao resfriamento.

Foi possível elaborar um protocolo de resfriamento a $-8^{\circ} \mathrm{C}$ de embriões de $P$. mesopotamicus, utilizando-se $9 \%$ de metanol e $17,1 \%$ de sacarose na solução crioprotetora por no mínimo seis horas.

\section{Referências}

AHAMMAD, M.M.; BHATTACHARYYA, D.; JANA, B.B. Effect of different concentrations of cryoprotectant and extender on the hatching of Indian major carp embryos (Labeo rohita, Catla catla, and Cirrhinus mrigala) stored at low temperature. Cryobiology, v.37, p.318-324, 1998.

AHAMMAD, M.M.; BHATTACHARYYA, D.; JANA, B.B. Hatching of common carp (Cyprinus carpio L.) embryos stored at 4 and $2{ }^{\circ} \mathrm{C}$ in different concentrations of methanol and sucrose. Theriogenology, v.60, p.1409-1422, 2003. 
CASTAGNOLLI, N. Espécies exóticas próprias para a piscicultura. In: CAStagnolli, N. (Ed.). Piscicultura de água doce. Jaboticabal: Funep, 1992. p.71-96.

DENNISTON, R.S.; MICHELET, S.; GODKE, R.A. Principles of cryopreservation. In. TIERSCH, T.R.; MAZIK, P.M. (Ed.). Cryopreservation in aquatic species. Baton Rouge: World Aquaculture Society, 2000. p.59-74.

FARKAS, T.; FODOR, E.; KITAJKA, K.; HALVER, J.E. Response of fish membranes to environmental temperature. Aquaculture Research, v.32, p.645-655, 2001.

HOLT, W.V. Basic aspects of frozen storage of semen. Animal Reproduction Science, v.62, p.3-22, 2000.

IBAMA. Estatística da pesca 2003: Brasil, grandes regiões e unidades da federação. Brasília: IBAMA, 2004. 137p.
KUSUDA, S.; TERANISHI, T.; KOIDE, N. Cryopreservation of chum salmon blastomeres by the straw method. Cryobiology, v.45, p.60-67, 2002.

RALL, W.F. Factors affecting the survival of mouse embryos cryopreserved by vitrification. Cryobiology, v.24, p.387-402, 1987.

SAS INSTITUTE. SAS/STAT software: changes and enhancements. Cary: SAS Institute, 1992. (SAS technical report P-229, release 6.07).

VISINTIN, J.A.; GARCIA, J.F.; PANTANO, T.; D’ÁVILAASSUMPÇÃO, M.E.O. Cryopreservation of mouse morulae in glycerol, sucrose and honeybee royal jelly. Brazilian Journal of Veterinary Research and Animal Science, v.37, p.307-311, 2000.

WOELDERS, H. Fundamentals and recent development in cryopreservation of bull and boar semen. The Veterinary Quarterly, v.19, p.135-138, 1997.

Recebido em 30 de março de 2007 e aprovado em 16 de julho de 2007 